\title{
Management of Obstructive Sleep Apnea with Implant Retained Mandibular Advancement Device
}

\author{
${ }_{1}^{1}$ Pokpong Amornvit, ${ }^{2}$ Dinesh Rokaya, ${ }^{3}$ Sahana Bajracharya, ${ }^{4}$ Konrawee Keawcharoen, ${ }^{5}$ Walop Supavanich
}

\begin{abstract}
Obstructive sleep apnea (OSA) is a condition which occurs from the narrowing of the upper airway. Obstructive sleep apnea in the edentulous patient can be caused by the anatomical obstruction of oropharyngeal space. In the elderly patients, the muscles of soft palate can easily be collapsed which can result in obstruction in respiratory passage. Oral appliance, namely, mandibular advancement device (MAD) is the recommended treatment appliance for the patient with mild to moderate OSA. In the elderly edentulous patients, OSA is worsening as these patients are difficult to treat with oral appliance due to with diminished vertical dimension and lack of retention for MAD. The use of osseointegrated dental implants and the locator attachments aid in the retention of the appliance provides support to the denture and the device, and also prevent trauma to the underlying mucosa. This case reports the technique of fabrication of MAD with elastic mandibular advancement (EMA) device to treat moderate OSA from implant retained complete dentures in maxilla and mandible in complete edentulous patient.
\end{abstract}

Keywords: Obstructive sleep apnea (OSA), Elastic mandibular advancement (EMA) device, Edentulous patient, Dental implant, Locator.

How to cite this article: Amornvit $P$, Rokaya D, Bajracharya $S$, Keawcharoen K, Supavanich W. Management of Obstructive Sleep Apnea with Implant Retained Mandibular Advancement Device. World J Dent 2014;5(3):184-189.

Source of support: Nil

Conflict of interest: None

\section{INTRODUCTION}

Obstructive sleep apnea (OSA) is a disorder characterized by repetitive episodes of complete (apnea) or partial (hypopnea) obstruction of the upper airway during sleep. ${ }^{1}$ Obstructive sleep apnea is a widely prevalent problem which

\footnotetext{
${ }^{1,4}$ Instructor, ${ }^{2,3}$ Resident, ${ }^{5}$ Otolaryngologist and Vice Director

1-3Maxillofacial Prosthetic Clinic, Department of Prosthodontics Faculty of Dentistry, Mahidol University, Salaya, Thailand

${ }^{4}$ Department of Oral and Maxillofacial Surgery, Golden Jubilee Medical Center, Mahidol University, Salaya, Thailand

${ }^{5}$ Department of Otolaryngology, Head and Neck Surgery Banphaeo Hospital, Samut Sakhon, Thailand

Corresponding Author: Pokpong Amornvit, Instructor, Maxillofacial Prosthetic Service, Faculty of Dentistry, Mahidol University 6 Yothi Street, Salaya, Thailand, Phone: +66-891616260, e-mail: pokpong_am@yahoo.com
}

increases the risk and development of chronic diseases, such as systemic hypertension, depression, stroke, angina and cardiac dysrhythmias. ${ }^{2}$ The diagnostic tools used for OSA are the polysomnography (PSG), questionnaire, lateral cephalometric radiograph, MRI and AHI index. Depending upon the severity, nonsurgical or surgical treatment is carried out. Nonsurgical treatment includes the behavior modification, pharmacotherapy, continuous positive airway pressure (CPAP) and oral appliance therapy, whereas, the surgical procedures include the uvulopalatopharyngoplasty and tongue base suspension. ${ }^{3}$ Oral appliance, such as mandibular advancement device (MAD) is mostly recommended for mild to moderate OSA or to patients who did not respond to $\mathrm{CPAP}^{4}$

There are many factors involved in the development of OSA. The extraction of teeth leads to the physiologic consequence of reduction of buccolingual and apico-coronal dimension of alveolar ridge. ${ }^{5}$ Thus, this results in the anatomical changes in the lower $2 / 3$ rd of the face. Intraorally, complete edentulism results in loss of vertical dimension of occlusion, change in position of mandible and tongue. ${ }^{6-8}$ These all changes can lead to OSA. Moreover, OSA can result from an anatomical obstruction of the oropharyngeal space, as the muscles of soft palate can easily collapse. ${ }^{9}$ The collapsed vertical dimension and absence of the teeth worsen the OSA by decreasing the treatment choices.

Dental implants are good options in edentulous patients for the better retention of the dental prosthesis. This case report describes the treatment sequence of the edentulous patient with moderate OSA using implants retained MAD with locator attachments.

\section{CASE REPORT}

A 62-year-old man visited the maxillofacial prosthetic clinic, with a complaint of difficulty in chewing with the removable partial denture and snoring at night with daytime drowsiness. He had been wearing the maxillary and mandibular partial dentures for over 7 years. No significant medical history reported related to the patient's condition. Intraoral examination revealed six remaining teeth upper right canine, upper right first premolar, lower left central incisor, lower left lateral incisor, lower left canine and lower right canine (Figs 1A and B) with periodontal and dental 

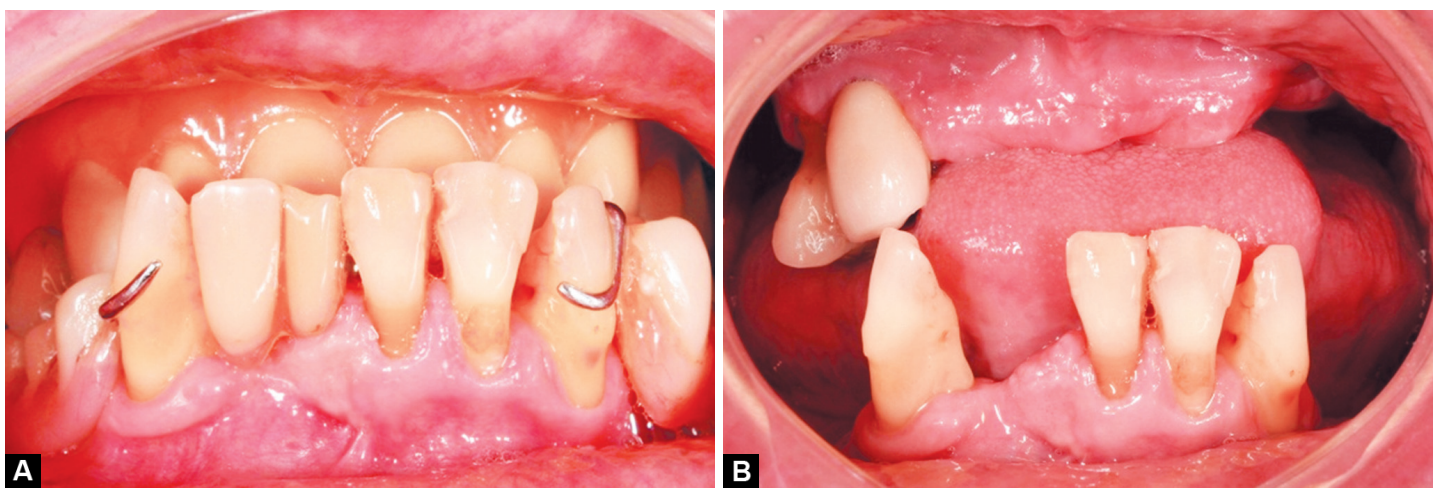

Figs $1 A$ and B: (A) Frontal view of the patient with maxillary and mandibular acrylic partial denture and $(B)$ frontal view of the patient without partial denture with few remaining natural teeth with poor prognosis
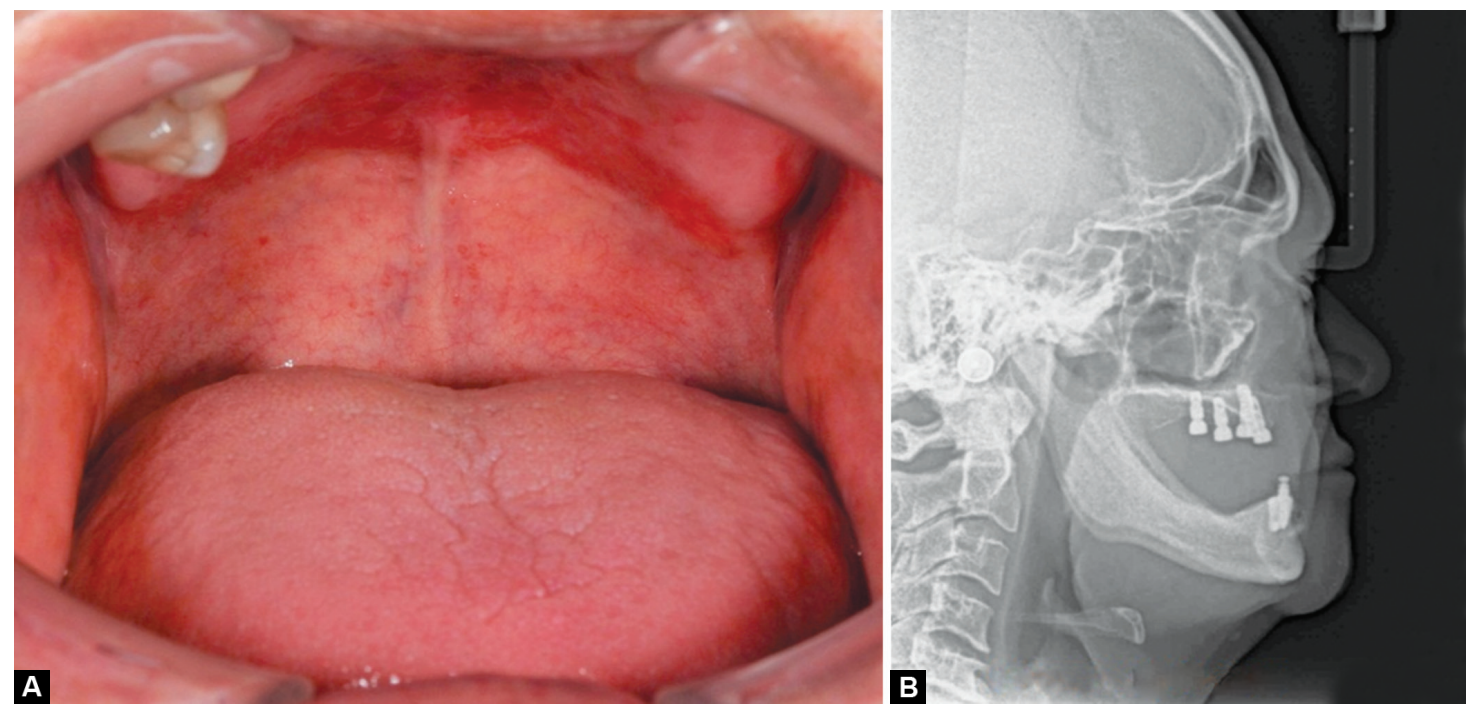

Figs 2A and B: (A) Examination of the soft palate showing Mallampati score 2 and oropharyngeal area and (B) examination of airway in radiographs

problems. The maxillary and mandibular partial dentures were old with worn acrylic teeth and in class III relation. The mucosa underneath the maxillary denture was inflamed from the ill-fitting denture. Evaluation of temporomandibular joint (TMJ) revealed no abnormality.

Sleep parameters were assessed. The facial profile was concave, neck circumference was $40 \mathrm{~mm}$ and BMI was 34.89 $\mathrm{kg} \mathrm{m}^{-2}$. The Malampati score was 3 (Figs 2A and B). The Epworth sleepiness scale was used to access the sleepiness and was found to be 13. An overnight PSG was done and the results are shown in Table 1. He was diagnosed with moderate OSA. The list of problems observed after the examination were as follows:

- Snoring with moderate OSA

- Partial edentulous maxillary and mandibular arch with ill-fitting denture

- Poor prognosis of remaining teeth from periodontal disease

- Severe resorption of the lower arch.

After clinical and radiographic examination, treatment options were discussed with patient. It was planned for implant retained maxillary and mandibular complete removable denture for esthetic and function and implant retained advancement MAD for the treatment of OSA.

\section{Phase I (Preparatory Phase)}

Maxillary and mandibular immediate complete dentures were fabricated in a conventional manner to obtain the lost vertical dimension (Ref). All the remaining teeth (maxillary four and mandibular three) were extracted and followed by the placement of five maxillary and three mandibular Implants (Osstem ${ }^{\circledR}$, Seoul, South Korea). Two mini-implants in the lower arch were also placed to retain the mandibular denture during the healing phase (Fig. 3). The immediate dentures were lined with the soft liner and loaded intraorally (Fig. 4).

\section{Phase II (Fabrication of Oral Appliance)}

Three months after the placement of implants (Figs 5A and $\mathrm{B})$, lower mini-implants were removed and male part of the locator (LOCATOR ${ }^{\circledR}$, Zest Anchors, Escondido, CA) 
Table 1: Result of polysomnography

\begin{tabular}{|c|c|c|c|c|c|c|c|c|c|}
\hline & \multirow{2}{*}{$\begin{array}{l}\text { TST } \\
\text { (min.) }\end{array}$} & \multicolumn{3}{|c|}{ Sleep stages (\%) } & \multirow{2}{*}{$\begin{array}{l}\text { AHI } \\
\text { (per hour) }\end{array}$} & \multirow{2}{*}{$\begin{array}{l}O D E \\
(\%)\end{array}$} & \multirow{2}{*}{$\begin{array}{l}R D I \\
(\%)\end{array}$} & \multirow{2}{*}{$\begin{array}{l}\text { MOS } \\
\text { (\%) }\end{array}$} & \multirow{2}{*}{$\begin{array}{l}\text { LOS } \\
(\%)\end{array}$} \\
\hline & & Light & Deep & REM & & & & & \\
\hline Without MAD & 290 & 60.57 & 6.13 & 3.30 & 27.8 & 24.2 & 30.5 & 85 & 75 \\
\hline $\begin{array}{l}\text { 1st night with } \\
\text { MAD }\end{array}$ & 421 & 54.2 & 40.46 & 3.6 & 22.7 & 18.7 & 25.3 & 95.2 & 78.4 \\
\hline $\begin{array}{l}\text { 30th night } \\
\text { with MAD }\end{array}$ & 430 & 51.2 & 60.46 & 2.6 & 15.6 & 10.7 & 21.6 & 97.6 & 84.3 \\
\hline
\end{tabular}

Total sleep time (TST); Apnea-hyponea index (AHI); Oxygen desaturation events (ODE); Respiratory disturbance index (RDI); Mean oxygen saturation (MOS); Lowest oxygen saturation (LOS)

were picked up in maxillary and mandibular dentures. Then, both dentures were duplicated by covering the occlusal, incisal and interdental area of the artificial teeth with the modeling wax (Carvex TT 100 soft, Carvex, Haarlem, Holland). The wax block were added on the posterior area of mandibular denture to have the anterior bite opening of about $4 \mathrm{~mm}$ between upper and lower incisal area of the newly fabricated denture during the advancement of the mandible (Figs 6A and B). The anterior bite opening allows the adequate space for the breathing. The mold were prepared by the duplication of waxed maxillary and mandibular dentures and packed with clear heat cure acrylic resin (Vertex Rapid Simplified, Amsterdam, Netherlands) to fabricate the two piece MAD. The male parts of the locators were picked up in the MAD fabricated with clear heat cure acrylic resin

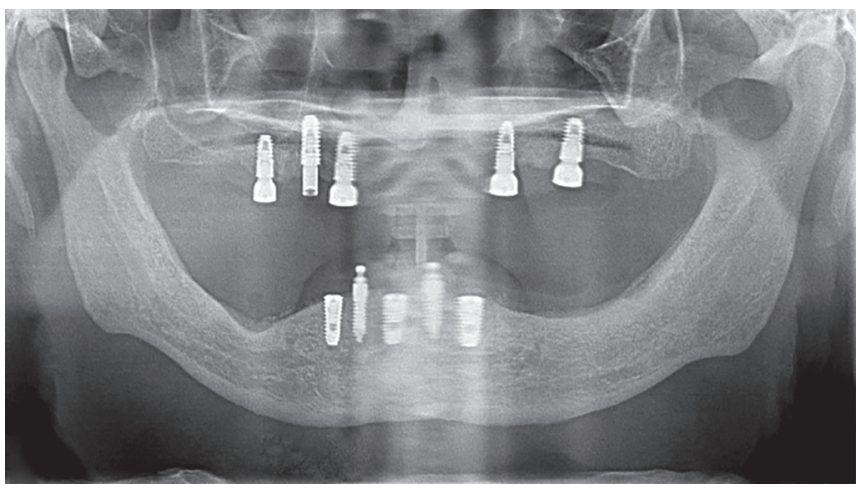

Fig. 3: After the extraction of remaining natural teeth, 4 implants were placed in maxillary arch and 3 in mandibular arch. Two mini-implants were placed in mandibular arch to support mandibular denture
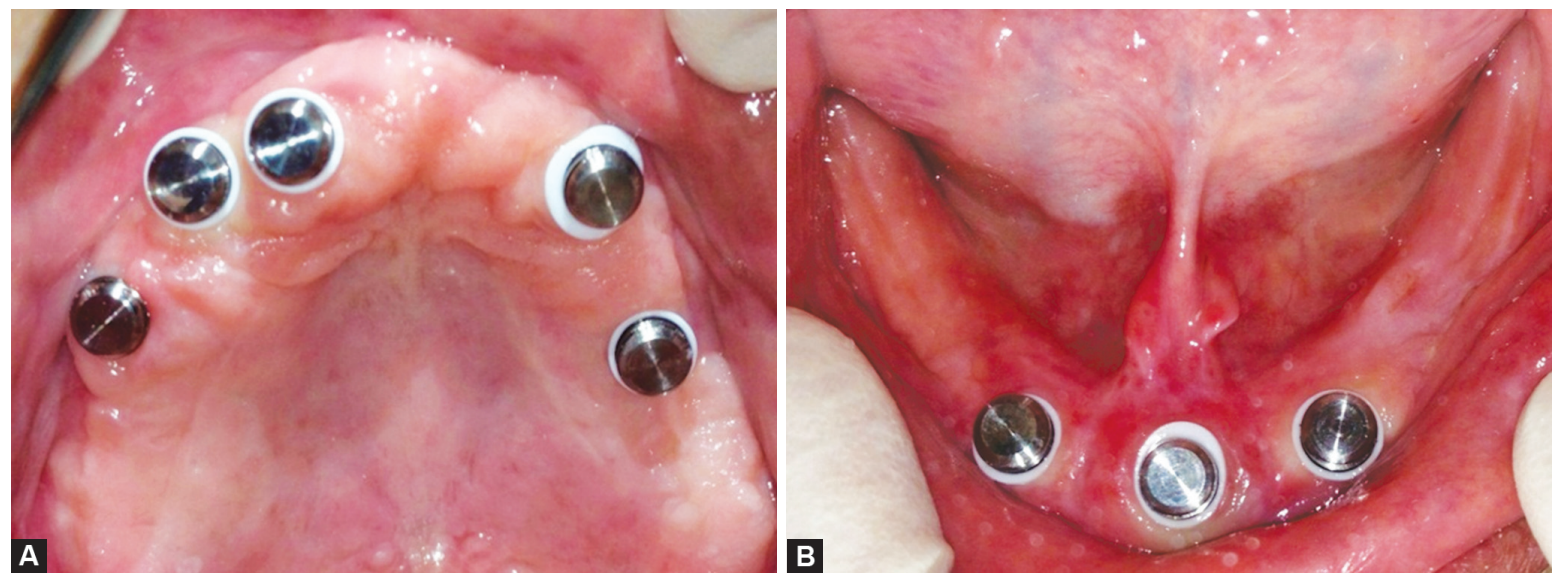

Figs 5A and B: (A) The maxillary denture was retained with 4 locators and $(B)$ the mandibular denture was retained with 3 locators for the retention and support (Fig. 7). Then, the plastic button hooks of elastic mandibular advancement (EMA) device (Myerson, IL, USA) were attached on the buccal aspect behind the canine region in maxillary and molar in mandibular of the MAD using light cure adhesive (Myerson EMA, Harrow middx, UK). For the horizontal advancement of the mandible, first $19 \mathrm{~mm}$ length elastic strap of EMA device was hooked on the plastic button hooks to activate the device (Figs 8A and B). Gradually in the subsequent follow-up visits, the elastic of shorter length of $17 \mathrm{~mm}$ with greater strength were used.

The primary objective of this device was to increase the space of airflow due to protrusion of mandible without increasing the vertical dimension of occlusion. Evaluation was made with full night PSG while MAD was in the mouth

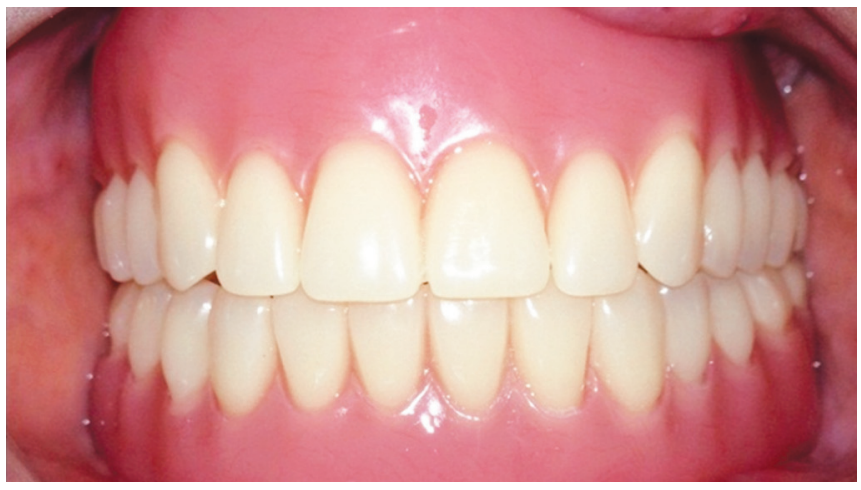

Fig. 4: Maxillary and mandibular complete dentures were inserted 

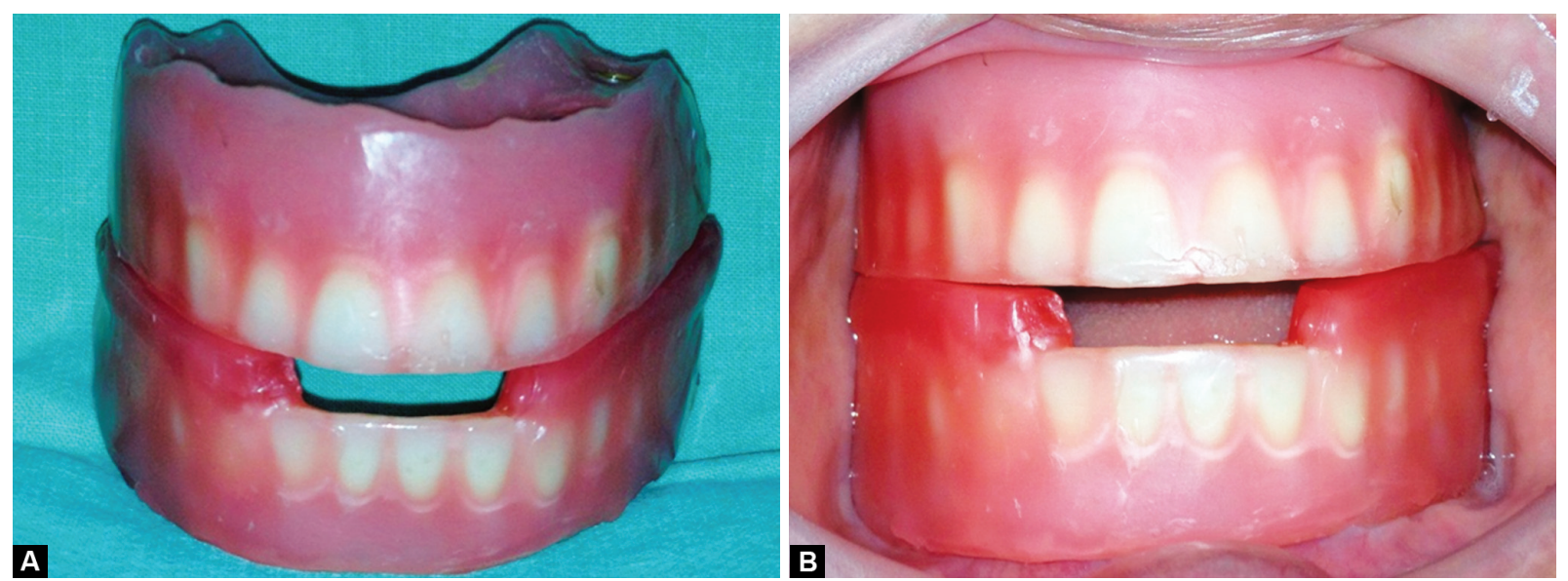

Figs 6A and B: (A) Maxillary and mandibular denture teeth along with interdental spaces were covered with modeling wax for the fabrication of MAD and (B) they were tried in the mouth
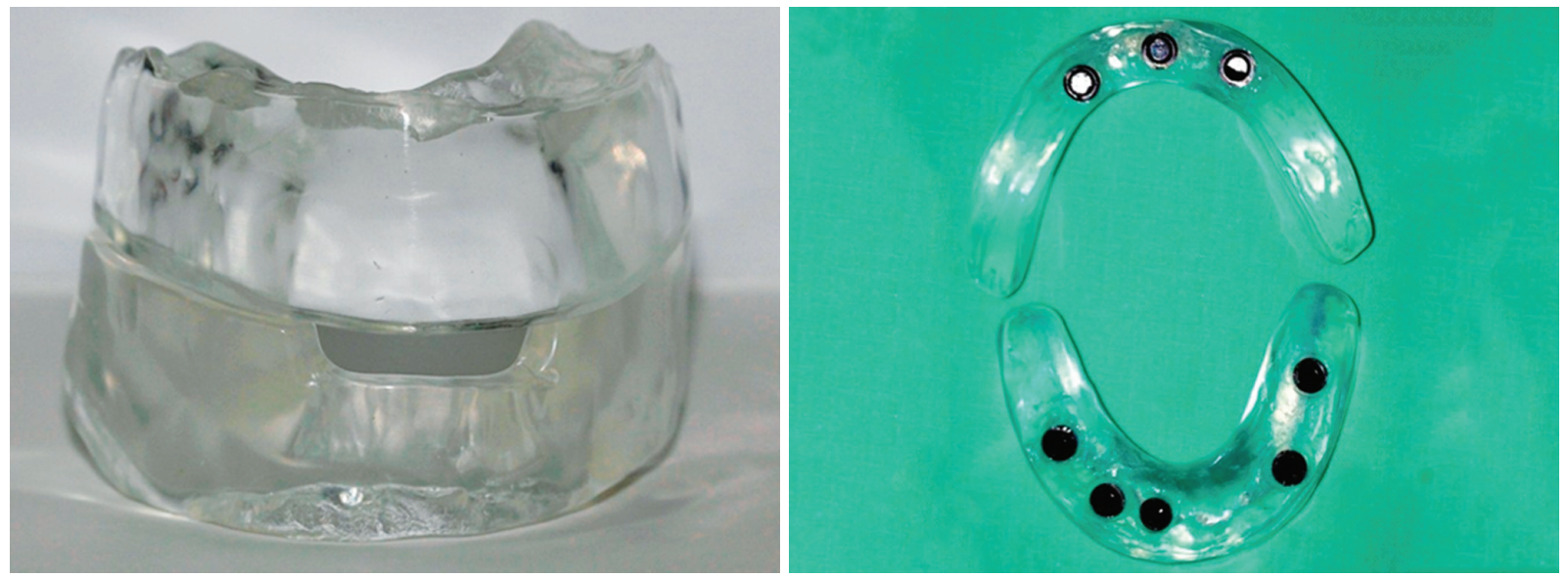

Fig. 7: The MAD device was fabricated from heat cure acrylic resin. The locators were attached to the MAD device

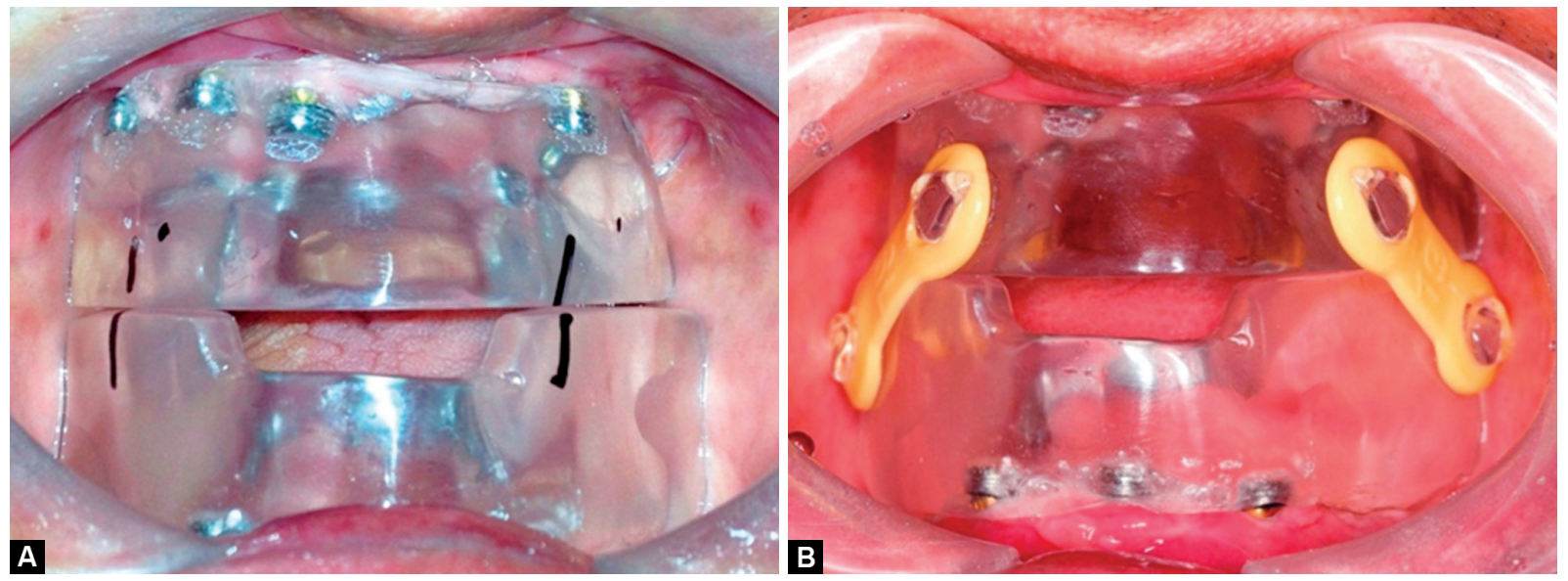

Figs 8A and B: (A) The amount of the mandibular advancement was calculated and marked, and (B) they were fixed with plastic plate

during the sleep. Initial evaluation of device with PSG was performed on the 1st day of insertion of the MAD and the second evaluation was performed on the 30 th day. The results are shown in Table 1. No TMJ dysfunction or masticatory muscle discomfort was detected at 2 weeks follow-up. The PSG result showed the improvement in the AHI score including various parameters. Patient's subjectively also informed the reduced daytime drowsiness and tiredness.

\section{DISCUSSION}

Snoring is a clinical sign of the OSA which results when the soft palate vibrates the pharyngeal space. ${ }^{1}$ OSA causes morbidity, particularly in terms of impairment of daytime functioning which directly impact on the quality of life and also could be life threatening. Nasal CPAP is considered as the primary treatment for the symptomatic patients with OSA. However, due to lack of patient compliance and 
discomfort, the acceptance has reduced. Various authors have presented different appliances to treat OSA. ${ }^{10-13}$ The randomized controlled trials have shown the effectiveness of oral appliance therapy in 50\% of patients for reducing mild to moderate OSA, including some patients with severe forms of OSA. This is associated with a significant improvement in symptoms, including snoring and daytime sleepiness. ${ }^{14}$ The oral appliances, e.g. MAD is getting popular due to its portability, unobtrusive, no noise and less cost. ${ }^{13-16}$ There are various parameters that influence the oral appliance, e.g. dimension of mandibular protrusion, sleep position, degree of sleep apnea and patient's body mass index (BMI). ${ }^{13}$ Presence of teeth ensure the retention and stability of the oral appliance. However, the loss of teeth cannot only compromise the retention but also worsen the OSA. Bucca et $\mathrm{al}^{16}$ reported the worsening of OSA from edentulism by reducing the retropharyngeal space and confirmed that the sleeping without denture can increase AHI index. Therefore in edentulous patient with OSA, the fabrication of the denture can help to position the tongue, obtain the lost vertical dimension and oral appliance can help to achieve a relaxed protrusive and vertical position of the mandible that reduces the airway obstruction during sleep. ${ }^{17,18}$

In the presented case, the patient chose to use oral appliance than CPAP which protrudes the mandible anteriorly and vertically to provide space in the upper airway. The genioglossus muscle and its associated tendon connects the tongue to the genial tubercle of the lingual aspect of the anterior mandible. Therefore, when the mandible is advanced, the tongue is also pulled forward and creates more space in the pharynx thus reduce the collapsibility of the airway and the tendency for snoring. ${ }^{11}$

Generally, the mandible may be advanced 6 to $10 \mathrm{~mm}$ or 50 to $75 \%$ of maximum protrusion horizontally and 10 to $15 \mathrm{~mm}$ vertically. ${ }^{20,21}$ More the mandible is protruded, more the airway is opened. However, an excessive protrusion may place the condyle in an uncomfortable position at or approaching the eminence which causes discomfort for the patient. The amount of vertical opening of the mandible can increase the airway somewhat as well, but may also cause discomfort. Thus, the mandible protrusion and vertical opening should be in a range that the patients can tolerate and feels comfort.

In the present study, elastic straps from EMA were used to treat OSA. EMAs are easy, non-invasive treatment for the OSA. EMA has the ability to adjust the amount of mandibular advancement by changing the elastic straps. Using elastics to pull the mandible forward, EMA allows lateral, vertical and antero-posterior movement of the mandible while advancing the mandible in a ventral and caudal direction. ${ }^{22}$ Dental implant is an accepted means of retention which has allowed an access to various treatment options for the edentulous patients. The minimum number of the implants suggested for the maxillary and mandibular implant retained overdenture are four and two respectively. The nonsplinted locator attachment was chosen to retain both the complete denture and MAD due to their resilient nature, requirement of less space in the denture and MAD and cost-effectiveness.

Apart from the benefits, the temporary symptoms that may be seen in some patients using MAD include dental, TMJ and myofacial pain; salivation, xerostomia and gingival irritations. ${ }^{19,20}$ Hence, the patient may need reassurance or adjustment to get beyond this period.

\section{CONCLUSION}

This clinical report describes the fabrication of two piece MAD from implant retained maxillary and mandibular complete denture. This method helps to increase the vertical dimension in edentulous patient with severe vertical loss and also advance the mandible forward to reduce the snoring. Implants and locator played a vital role in the retention of the MAD. The MAD decreased the AHI score of the patient.

\section{REFERENCES}

1. Young T, Evans L, Finn L, Palta M. Estimation of the clinically diagnosed proportion of sleep apnea syndrome in middle-aged men and women. Sleep 1997;20(9):705-706.

2. Magliocca KR, Helman JI. Obstructive sleep apnea: diagnosis, medical management and dental implications. J Am Den Assoc 2005;136(8):1121-1129.

3. Couch ME, Senior B. Nonsurgical and surgical treatments for sleep apnea. Anesthesiol Cli North America 2005;23(3):525-534.

4. Kushida CA, Morgenthaler TI, Littner MR, Alessi CA, Bailey D, Coleman J Jr, et al. Practice parameters for the treatment of snoring and obstructive sleep apnea with oral appliances: an update for 2005. Sleep 2006;29(2):240-243.

5. Hansson S, Halldin A. Alverolar ridge resorption after tooth extraction: a consequence of a fundamental principle of bone physiology. J Dent Biomech 2012;3:1-8.

6. Unger JW. Comparison of vertical morphologic measurements on dentulous and edentulous patients. J Prosthet Dent1999;64(2): 232-234.

7. Lambadakis J, Karkazis HC. Changes in the mandibular rest position after removal of remaining teeth and insertion of complete dentures. J Prosthet Dent 1992;68(1):74-77.

8. Erovigni F, Graziano A, Ceruti P, Gaassino G, De Lillo A, Carossa S. Cephalometric evaluation of the upper airway in patients with complete dentures. Minerva Stomatol 2005;54(5): 293-301.

9. Gupta P, Thombare R, Pakhan AJ, Singhal S. Cephalometric evaluation of the effect of complete dentures on retropharyngeal space and its effect on spirometric values in altered vertical dimension. Int Scholarly Res Network Dent 2011;516969.

10. Taner T, Aydinatay BS, Turkyilmaz L, Demir AU. The use of modified mandibular advancement appliance in the treatment 
of a partially edentulous patient with obstructive sleep apnea. Hacettepe Dişhekimliği Fakültesi Dergisi 2007;31(3):82-87.

11. Flanagan D. A removable snore reduction appliance for a mandibular edentulous patient. J Oral Implant 2009;35(5): 221-229.

12. Maurer JT, Huber K, Verse T, Hörmann K, Stuck B. A mandibular advancement device for the ENT office to treat obstructive sleep apnea. Otolaryngology-Head and Neck Surgery 2007;136(2): 231-235.

13. Ferguson KA, Cartwright R, Rogers R, Schmidt-Nowara W. Oral appliances for snoring and obstructive sleep apnea: a review. Sleep 2008;29(2):244-262.

14. Ng A, Gotsopoulos H, Darendeliler AM, Cistulli PA. Oral appliance therapy for obstructive sleep apnea. Treat Respir Med 2005;4(6):409-422.

15. Hoffstein V. Review of oral appliances for treatment of sleepdisordered breathing. Sleep Breath 2007;11(11):1-22.

16. Bucca C, Carossa S, Pivetti S, Gai V, Rolla G, Preti G. Edentulism and worsening of obstrucrtive sleep apnea. Lancet 1999; 353(9147):121-122.
17. Robertson CJ. Treatment of obstructive sleep apnea in edentulous patients - design of a combination appliance: a case study. NZ Dent J 1998;94(7):123-124.

18. Meyer JB, Knudson RC. Fabrication of a prosthesis to prevent sleep apnea in edentulous patients. J Prosthet Dent 1990;63(4): 448-451.

19. Mehta A, Qian J, Petocz P, Darendeliler MA, Cistulli PA. A randomized, controlled study of a mandibular advancement splint for obstructive sleep apnea. Am J Respir Crit Care Med 2001;163(6):1457-1461.

20. de Almeida FR, Bittencourt LR, de Almeida CI, Tsuiki S, Lowe AA, Tufik S. Effects of mandibular posture on obstructive sleep apnea severity and the temporomandibular joint in patients fitted with an oral appliance. Sleep 2002;25(5):507-513.

21. Mehta A, Qian J, Petocz P, Darendeliler MA, Cistulli PA. A randomized, controlled study of a mandibular advancement splint for obstructive sleep apnea. Am J Respir Crit Care Med 2001;163(6):1457-1461.

22. de Almeida FR, Bittencourt LR, de Almeida CI, Tsuiki S, Lowe AA, Tufik S. Effects of mandibular posture on obstructive sleep apnea severity and the temporomandibular joint in patients fitted with an oral appliance. Sleep 2002;25(5):507-513. 